\title{
INUNDATION AND DESTRUCTION ON THE BOLIVAR PENINSULA DURING HURRICANE
} IKE

\author{
Andrew B. Kennedy ${ }^{1}$, Matild Dosa ${ }^{1}$, Francisco Zarama ${ }^{1}$, Uriah Gravois ${ }^{2}$, Brian Zachry ${ }^{3}$, \\ Spencer Rogers ${ }^{4}$, and Asbury Sallenger ${ }^{5}$
}

\begin{abstract}
Hurricane Ike was one of the most destructive storms in US history, and caused catastrophic damage to the Bolivar Peninsula, Texas, with over $4.7 \mathrm{~m}$ measured surge at the Gulf of Mexico shoreline. This surge began unusually early, reaching $2.5 \mathrm{~m}$ at 25 hours before landfall while winds were both weak and shore-parallel. The strong forerunner surge resulted from Coriolis effects on the wind-driven alongshelf current, and occurred previously in the similarly destructive 1900 and 1915 Galveston Hurricanes. In onshore areas with strong wave action, damage was near-total to buildings whose flooring systems could be reached by wave crests, while slightly more elevated buildings survived almost unscathed. There was much less of a correlation between survival and elevation in areas with small waves.
\end{abstract}

Keywords: Hurricane Ike; storm surge; wave damage

\section{INTRODUCTION}

Hurricane Ike made landfall on September 13, 2008 at Galveston, Texas, with 1-min maximum sustained winds of $95 \mathrm{knots}(49 \mathrm{~m} / \mathrm{s})$, and a very large wind field with tropical storm force velocities extending to more than $300 \mathrm{~km}$ from the storm center (Berg, 2009). Hurricane Ike caused an estimated \$27 billion in damages, making it one of the most destructive US hurricanes ever. The low-lying Bolivar Peninsula just east of Galveston experienced the most severe conditions of any inhabited area, with near-total destruction in some areas (Kraus et al., 2009; Kennedy et al., 2010b). This is a popular summer beachgoing area and consists largely of wood-framed single family residences elevated above grade on wood pilings. Here, shorelines typically eroded on order of $50 \mathrm{~m}$ and usually undermined foundation pilings for the first row of houses, causing widespread collapse. The large waves and surge destroyed many more houses, with some areas experiencing more than 90 percent total destruction of houses. Figure 1 shows satellite photographs of the area taken before and after Hurricane Ike. Severe destruction is obvious, as is the sandy overwash and shoreline erosion. Most of the $30 \mathrm{~km}$ length of the Bolivar coast showed similar scenes. Damage further inland, although still severe, decreased in its totality of destruction. This widespread damage and the strong flooding experienced in this region forms the topic of this paper. We will first examine the surge, focusing on the early forerunner surge, which was unpredicted although there have been historical precedents. Next we will study building destruction on Bolivar and potential links between elevation and survival in differing wave climates.

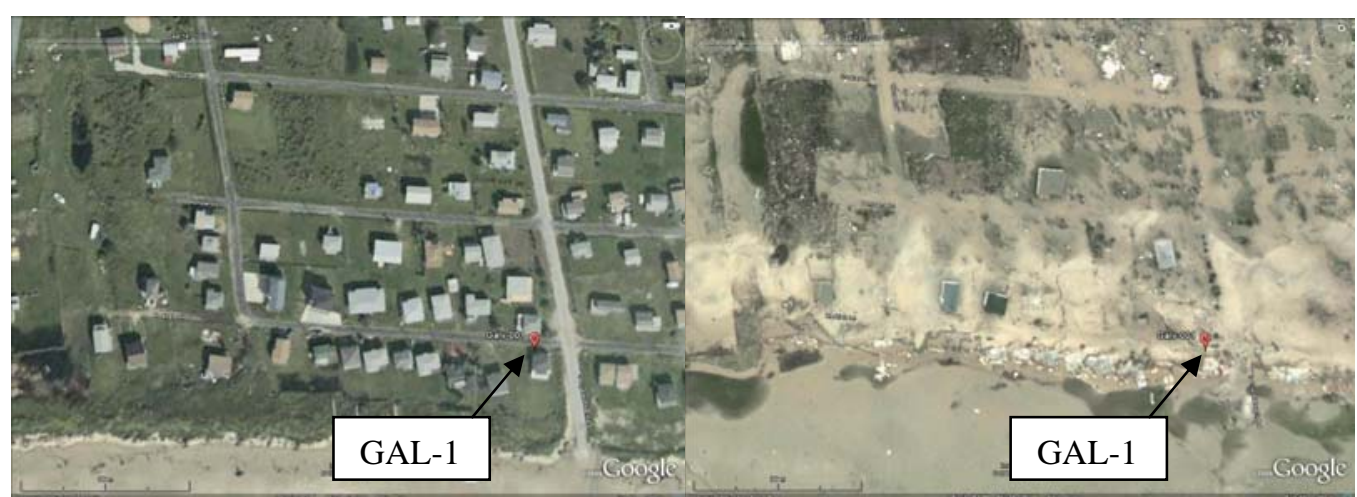

Figure 1. Satellite images of the Bolivar Peninsula from Google Earth taken (left) before; and (right) after Hurricane Ike, showing severe shoreline erosion and near-complete destruction of pile-elevated housing stock. USGS temporary gauge GAL-1 is located as shown.

\footnotetext{
${ }^{1}$ Department of Civil Engineering and Geological Sciences, University of Notre Dame, 156 Fitzpatrick Hall, Notre Dame, IN, 46556, USA

${ }^{2}$ Department of Civil and Coastal Engineering, University of Florida, 365 Weil Hall, Gainesville, FL, USA 32611.

${ }^{3}$ AIR Worldwide, 131 Dartmouth Street Boston, MA 02116

${ }^{4}$ North Carolina Sea Grant, 5600 Marvin K. Moss Lane Wilmington, NC 28409

${ }^{5}$ US Geological Survey, St. Petersburg Coastal and Marine Science Center 600 Fourth Street South St. Petersburg, Florida 33701
} 


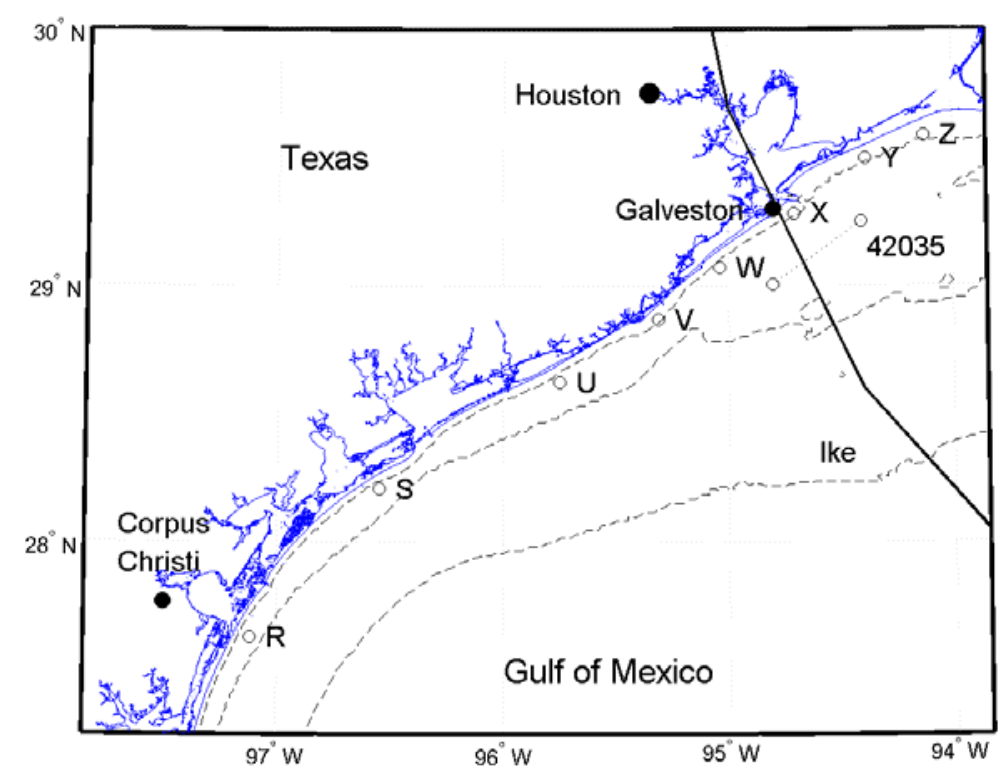

Figure 2. Hurricane lke's best track and rapidly-deployed gauges R-Z. The $10 \mathrm{~m}, 20 \mathrm{~m}$, and $50 \mathrm{~m}$ contours are shown as dotted lines.

\section{MEASUREMENTS OF FORERUNNER SURGE}

Two days before Ike's landfall, the authors deployed nine wave/surge gauges using helicopters (see Kennedy et al., 2010a for instrument details and deployment strategies) to cover $370 \mathrm{~km}$ of coastline between Corpus Christi, Texas and the Texas-Louisiana border as shown in Figure 2. Eight of these gauges were retrieved post-storm, while the ninth was lost. These instruments included Gauge Y, which was located directly offshore of the Bolivar Peninsula. Additional water level data was available from USGS rapidly-deployed surge gauges (East et al., 2008). Of these, gauges GAL-1 and GAL-2 were on the open coast of the Gulf of Mexico, and $2.1 \mathrm{~km}$ inland at the Gulf Intracoastal Waterway (GIWW), respectively. Although these gauges only sampled the water level at a rate of one minute, the data could be processed to estimate some basic wave parameters using variances about the slowly moving mean (Kennedy et al., 2010b). Figure 3 shows gauge locations on and near the Bolivar Peninsula.

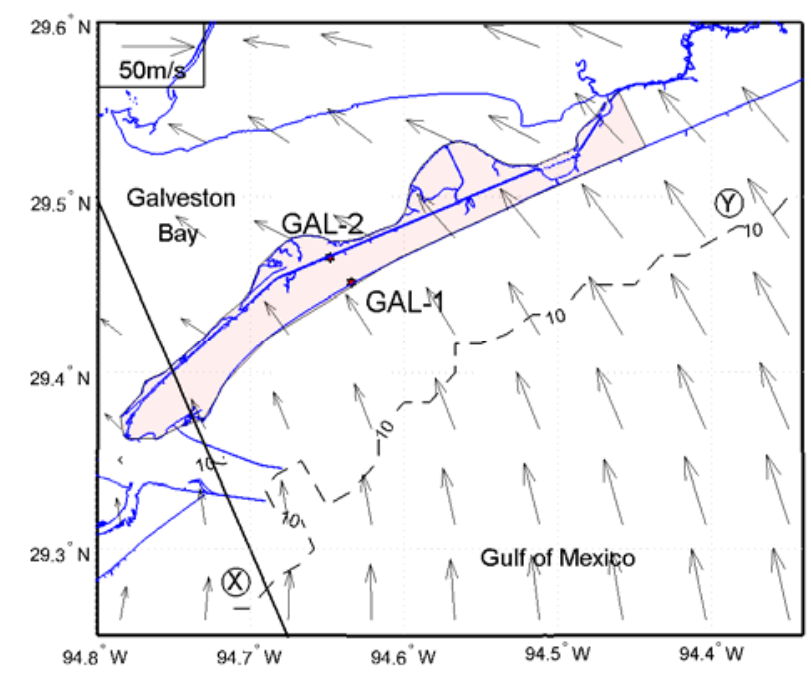

Figure 3. Small scale zoom on the Bolivar Peninsula showing the wind field and wave/surge measurement locations. The vector wind field is shown at landfall. Bathymetry contours are shown as dashed lines. USGS gauges GAL-1 and GAL-2, and author-deployed gauges $X$ and $Y$ are plotted at their respective locations. The Bolivar Peninsula is shaded. 
Figure 4 shows time series of surge measured at gauges X, Y, GAL-1 and GAL-2. Of these, surge was largest at GAL-1 with a maximum of just over $4.7 \mathrm{~m}$, but exceeded $4 \mathrm{~m}$ at all gauges but $\mathrm{X}$, which was directly at landfall. All gauges on the open coast (X, Y, GAL-1) additionally showed a very strong, forerunner surge that exceeded $2.2 \mathrm{~m}$ by 15 hours before landfall, with a smaller forerunner at GAL-2 on the GIWW. This forerunner surge was unpredicted, flooding coastal roads at least 22 hours before landfall, preventing evacuation and leading to dangerous rescues. Interestingly, winds during this time were not typical for storm surge of this magnitude. $\mathrm{H}^{*}$ wind post-storm reconstructions (Powell et al., 1998) show that at 15 hours before landfall, winds near Bolivar were only bordering on tropical storm strength and were actually directed offshore rather than onshore. This is contrary to expected conditions for surge, which normally feature strong offshore-to-onshore winds (Resio and Westerink, 2008).
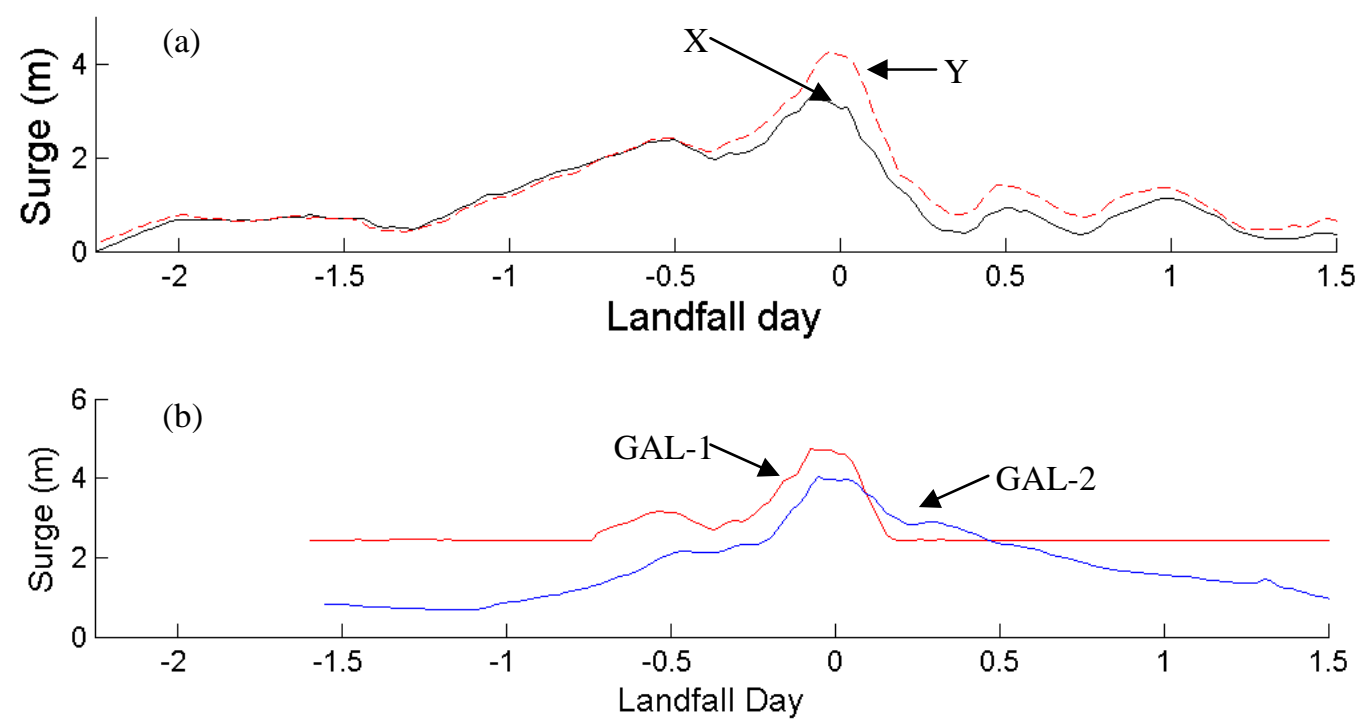

Figure 4. Measured storm surge (a) authors' gauges offshore of the Bolivar Peninsula; and (b) overland surge on Bolivar from US Geological Survey temporary gauges. All surge is in NAVD88 datum.

This large forerunner surge with contrary winds has historical precedent in this region: more than a half day prior to landfall in the Great Galveston Hurricane of 1900, local meteorologist Isaac Cline sent a telegram to the Washington, DC head office of the National Weather Service stating that water was, "overflowing low places south portion of city three to four blocks from beach. Such high water with opposing winds never observed previously" (Garriott, 1900). A similar forerunner surge was noted in the 1915 Galveston Hurricane, and even Hurricane Carla (1961), which made landfall 100s of km further south and forced a very large surge near Galveston while winds were shore-parallel. Unfortunately, one commonality between these storms is that all occurred many decades ago, and memory of the dangerous forerunner surge had diminished by the time of Ike's landfall in 2008. In part because of this, many residents were not prepared for the large early inundation and were trapped when the only bridge off the Peninsula became flooded.

This large forerunner surge appears to be a secondary effect of alongshore winds acting over the wide and shallow Louisiana-Texas (LATEX) shelf. Because of Ike's enormous size, these strong winds acted over a very large area and generated a correspondingly large area of strong alongshore currents which approached $200 \mathrm{~km}$ in cross-shore extent. These currents were acted on by Coriolis forces, which in the steady-state will cause a geostrophic setup of

$$
\eta_{c}=\int f V / g d x
$$

where $x$ increases along a transect toward shore, $f$ is the Coriolis parameter, $g$ is gravitational acceleration, and $V$ is the depth-averaged velocity perpendicular to the transect. Thus, a large geostrophic setup will be forced by strong alongshelf currents over a wide shelf: a depth-averaged current of $1 \mathrm{~m} / \mathrm{s}$ at 30 degrees north latitude with the shore on the right hand side would force a 
geostrophic setup of $1.5 \mathrm{~m}$ on a $200 \mathrm{~km}$ wide continental shelf. These are large numbers, and are only plausible here because of the extremely wide and shallow LATEX shelf and Ike's enormous size. More details are given in Kennedy et al. (2011), including numerical comparisons showing directly how neglecting Coriolis forces removes the forerunner surge completely and is particularly important in inland bays.

\section{BUILDING DAMAGE ON THE BOLIVAR PENINSULA}

The Bolivar Peninsula saw by far the most comprehensive destruction of any location during Hurricane Ike. Its very low elevations of around $2 \mathrm{~m}$ combined with the high surge and open coast location led to entire neighborhoods being destroyed, as shown in Figure 1, with nothing remaining but piles and foundation slabs. To evaluate this damage and connect it to the observed waves and surge, the authors performed damage surveys in many of these neighborhoods (Kennedy et al., 2010b). In locations directly on the Gulf of Mexico coast, almost all houses were pile-elevated; thus the survey focused on building elevations. This was particularly important as the damage mechanism for most houses appeared to be waves impacting on the underside of flooring systems, destroying the floor joists, and removing the house from its piles. There were very few seriously damaged houses, as they tended to either survive with relatively minor losses of outside staircases, utility connections, and lower breakaway walls, or were destroyed completely and the remains swept away by the floodwaters. Figure 5 shows survival and destruction of houses in the Bolivar area near the Gulf of Mexico. The most important feature is the very strong division in elevation between survival and destruction. This is on the order of $0.5 \mathrm{~m}$ and appears to be related to whether waves riding on top of surge could or could not reach the elevated flooring systems. For houses with lower elevations, the waves uniformly destroyed them, while houses at higher elevations survived.

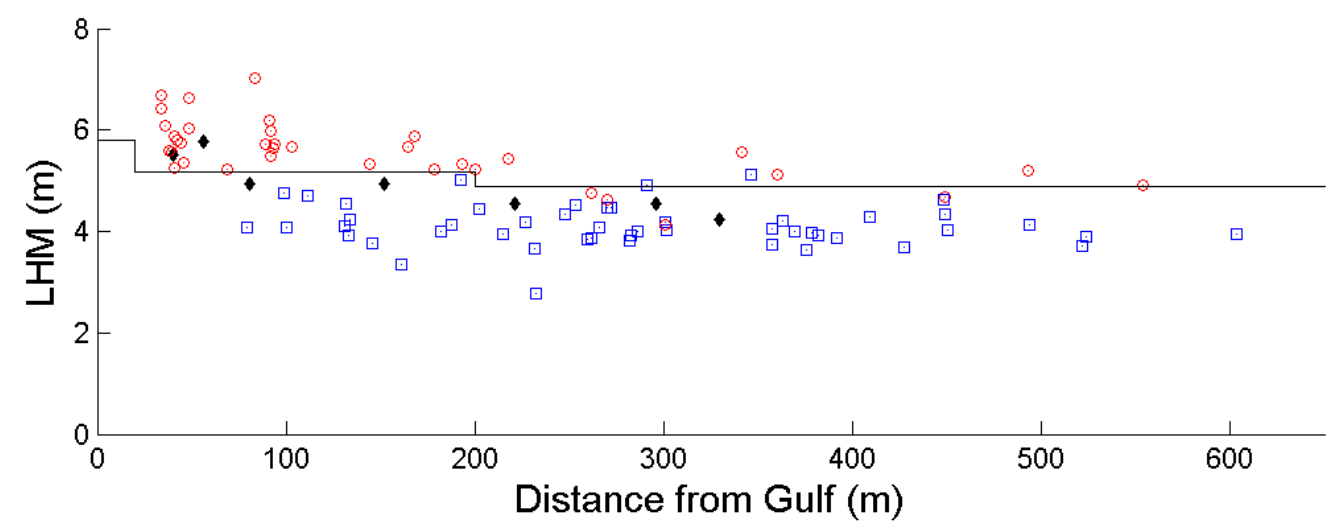

Figure 5. Survival and destruction with increasing distance from the Gulf of Mexico shoreline in The Biscayne, Salt Cedar, and Johnson Crawford areas. ( $\odot)$ Surviving Houses; $(\square)$ destroyed houses; $(\diamond)$ Houses surviving with noted wave damage. The elevation of wave damage for these houses was typically $0.25-0.3 \mathrm{~m}$ above the Lowest Horizontal Structural Member (LHM) elevation shown here. The solid line gives the approximate 1993 FEMA Base Flood Elevation (BFE) with distance inland.

This strong link between survival and destruction and building elevation was not as visible in areas further from the Gulf of Mexico. Here, as shown in Figure 6, buildings also uniformly survived at higher elevations, but many buildings also survived at low elevations, even at-grade homes built just above sea level. This may be contrasted with the sharp division in elevation between survival and destruction shown in Figure 5. Damage in these regions also differed. Near the Gulf of Mexico, the surrounding ground level infrastructure (e.g., sheds) were not only destroyed, but completely swept from the area. Nearer to the Intracoastal Waterway, more than $2 \mathrm{~km}$ from the open Gulf, not only did houses survive when completely inundated, but picket fences, plastic netting, and other flimsy objects were inundated but undamaged. 


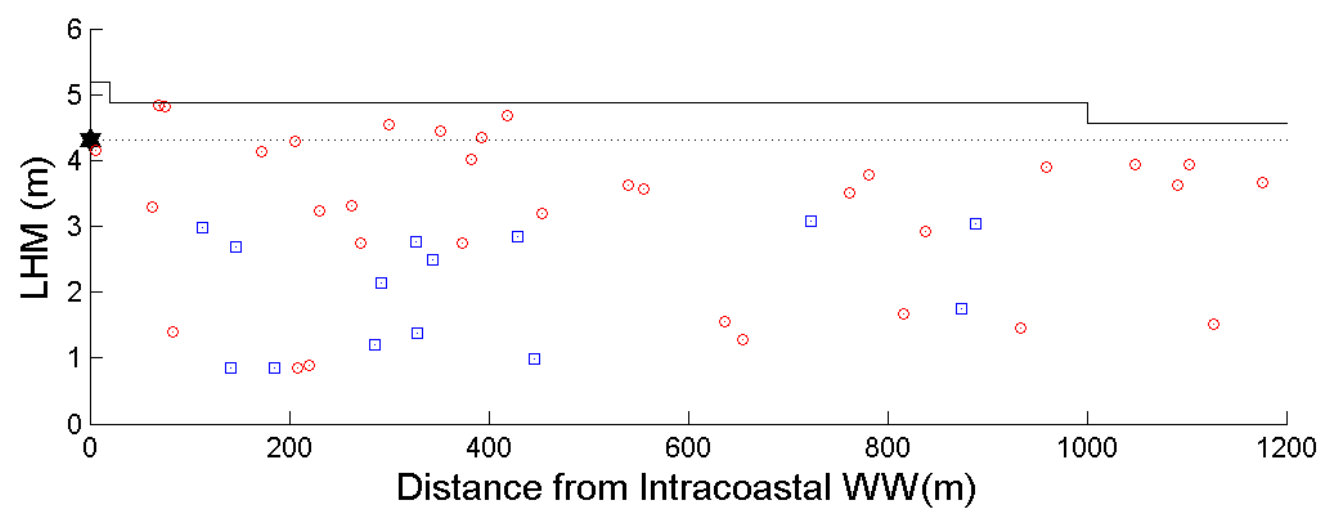

Figure 6. Survival and destruction of houses near USGS gauge GAL-2 on the GIWW. ( $)$ Surviving houses; ( $\square$ ) destroyed houses. The symbol ( elevation over the course of the storm at the location of GAL-2. The solid line gives the approximate 1993 FEMA BFE with distance inland from the Gulf Intracoastal Waterway.

All of these areas were strongly inundated, and lie within FEMA V-Zones, which are predicted to have the most severe wave action. Thus, pre-storm predictions of damage would be similar in both regions. However, the actual wave action experienced was much different close to the open coast compared to that far from the Gulf of Mexico, as might be expected. Figure 7 shows measurements of wave heights derived from USGS pressure measurements. (For details on the analysis which, because of the USGS pressure sampling rate, is not standard, see Kennedy et al., 2010b.) This analysis shows large waves approaching $1.8 \mathrm{~m}(6 \mathrm{ft})$ significant wave height at gauge GAL-1 which, after shoreline erosion, was on a small bluff immediately adjacent to the open Gulf of Mexico. These large waves riding on top of the surge shown in Figure 4 were then able to destroy houses low enough that they could reach the flooring systems. Houses surviving the storm were high enough to be outside this danger zone. The situation at gauge GAL-2 (located $1 \mathrm{~km}$ inland at the GIWW) is completely different. It should be noted that wave height estimates at this gauge have a greater uncertainty because of the sampling rate, but it is certain that wave heights are significantly smaller than those measured on the open coast at gauge GAL-1. This large difference in wave heights leads to vastly different destruction patters (Figures 5-6). Waves at GAL-1 were large and all buildings within reach were destroyed, while waves were small at GAL-2. Some houses were still destroyed at GAL-2 by the rising surge (and may have simply floated away if lightly attached to pilings), but inundation did not necessarily bring immediate destruction.

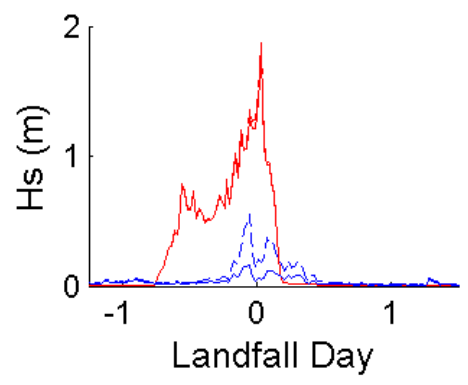

Figure 7. Time series of Significant Wave Height at USGS gauges GAL-1 (red) and GAL-2 (blue). Solid and dashed lines give approximate lower and upper bounds for estimates of wave height and overall inundation (sometimes obscured).

\section{DISCUSSION AND CONCLUSIONS}

Hurricane Ike may have been the most severe event in the recorded history of the Bolivar Peninsula, but will almost certainly be repeated at some time. Hopefully, by this time both 
understanding of the surge magnitude and timing, and building design and construction will have advanced enough that the widespread destruction seen in 2008 will not be repeated.

The large forerunner surge during Hurricane Ike was generated by Coriolis forces acting on a wide region of alongshore currents on the LATEX shelf. This was almost certainly the same phenomenon seen during the early surge in both the 1900 and 1915 Galveston Hurricanes. The Ike forerunner was not forecasted: this remains a research gap that needs to be investigated in the near future. Because alongshore currents are strongly dependent on bottom stresses, the accurate parameterization of bottom friction on the shallow shelf becomes much more important for forerunners than for typical cross-shore driven surge. In addition to the LATEX shelf, forerunners may also be generated elsewhere in the US and at other locations.

In areas with large waves, damage to houses was almost total when waves reached the flooring systems. In contrast, damage was much less severe in areas where waves were smaller, though both areas shown here were in FEMA V-zones. The decay in waves across the peninsula was clear, but the prediction of waves through bushes, fences, houses, roads, cars, and other assorted roughness and obstructions is not a simple task. Similarly, the height where waves begin/cease to destroy flooring systems is a leading order problem, but is not well known. Overall, the behavior of waves in flooded overland areas is an area ripe for further study.

\section{ACKNOWLEDGEMENTS}

Funding for this work was provided in part by the National Science Foundation, Florida Sea Grant, the University of Florida, the University of Notre Dame, the Florida Department of Environmental Protection, the US Geological Survey, and the University of Notre Dame.

\section{REFERENCES}

Berg, R. (2009). Tropical Cyclone Report. Hurricane Ike. National Hurricane Center Report TCRAL092008, 51 pp.

East, J.W., Turco, M.J., and Mason Jr., R.R. (2008). Monitoring Inland Storm Surge and Flooding from Hurricane Ike in Texas and Louisiana, September, 2008. USGS Open File Report 20081365, http://pubs.usgs.gov/of/2008/1365/ .

Garriott, E.B., (1900). “West Indian hurricane of September 1-12, 1900”. Mon. Wea. Rev. 43, 405-410.

Kennedy, A.B., Gravois, U., Zachry, B., Luettich, R., Whipple, T. Weaver, R., Reynolds-Fleming, J. Chen, Q., and Avissar, R. (2010a). "Rapidly installed temporary gauging for waves and surge, and application to Hurricane Gustav", Continental Shelf Research, in press, doi:10.1016/j.csr.2010.07.013.

Kennedy, A.B., Rogers, S., Sallenger, A., Gravois, U., Zachry, B., Dosa, M., and Zarama, F. (2010b). "Building Destruction from Waves and Surge on the Bolivar Peninsula during Hurricane Ike," $J$. Waterway, Port, Coastal and Ocean Eng.-ASCE, in press, doi:10.1061/(ASCE)WW.19435460.0000061.

Kennedy, A.B., Gravois, U., Zachry, B.C., Westerink, J.J., Hope, M.E., Dietrich, J.C., Powell, M.D., Cox, A.T., Luettich, R.L., and Dean, R.G. (2011). "Hurricane Ike Forerunner Surge: Origin and Implications", Submitted to Bulletin of the American Meteorological Society, 06/10.

Kraus, N.C., and Lin L. (2009). "Hurricane Ike along the upper Texas Coast: an introduction”. Shore and Beach 77, 3-8.

Powell, M.D., Houston, S.H., Amat, L.R., and Morriseau-Leroy, N. (1998). “The HRD real-time hurricane wind analysis system”. J. Wind Engineer. Indust. Aerodyn. 77\& 78, 53-64.

Resio, D.T. and Westerink, J.J. (2008). "Hurricanes and the Physics of Surges”, Physics Today, 61, 33-38. 